\title{
Inhalts= Derzeidnis.
}

Sette

I. Prălenglifte, Borberfamminng, Iagesorbnung ufm. . . . . . 1-26

II. Berganblungen bes Benofenfdaftstages.

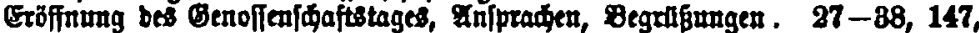

Beridt bes Inualts

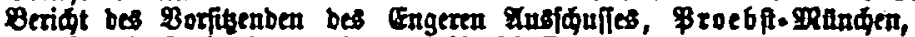

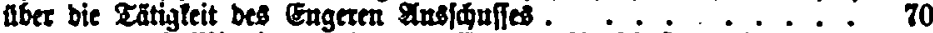

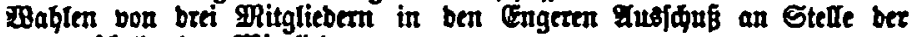
ausfaribenben 9 Ritglieber ... . . . . . . . . 72

Belalusfafiung llber ben Dut bes näbifen Benofienjdaftetages .... 73

Beriकt llber bie Silfslaffe - bie Mubegegaltslaffe - bie \$itwen- unb

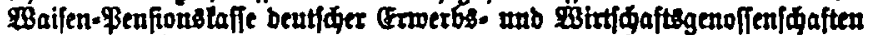

\$ahlen bon brei 9Ritgliebern in ben Borfianb ber Silfslate nad bem

Statut $\$ 8$ ber Jiffotafle . gemeinen Bexbanb nad \& 4 bes Statuts bes SAllgemeinen Berbanbes

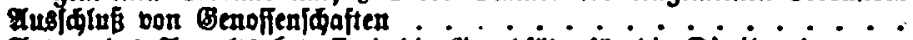

Intrag bes anmalts betreffenb bie Branbjake fut bie Dibibenbenber.

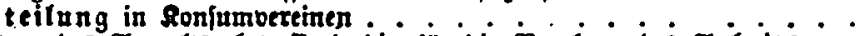

Intrag bes Inwalts betreffenb bie für bie segelung bes arbeitsver: Gáttniffes ber \&agerhalter masigebenben Branbläte. . . . .

Berwerbereditide Beptimmungen fur Sonfumbereine ....... 120

Die Motwenbigleit ber \$arenunterfudungen (zurudgeftelit). . . 137

\$intige Fetoffragen aus bem Spattafienverlehr 138

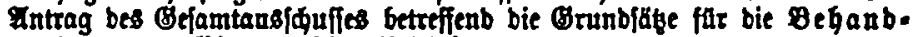
lung ber Biroberbinbliqteiten

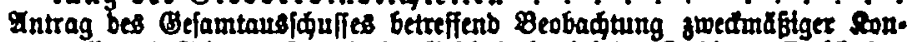

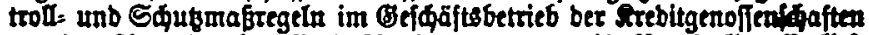

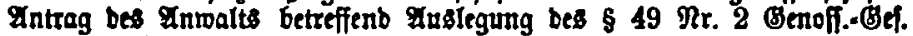
(zuradgezogen) . . . . . . . . 178

Exfabrungen mit bem B̈enoffenjdaftegeles . . . . . . . 190

Intrag bes Innwalts betreffenb anberung bes $\$ 48$ Pol. b bes Statuts bes gllgemeinen Berbanbes ..... 201

Braltifie Effabrungen mit ben Danbwerlergenolienibaften: . 205

antrag bes inmalts betreffenb ben Entwurf eines Befebes zur cer. Ielderung bes 20 éfielprotefies . . . . . . . . .

Intrag bes Inwalts betuffenb bie Shaffung von gRafiegcla, bie os ben

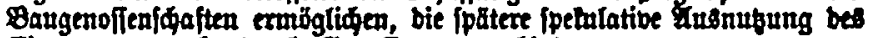
Eigentamberwerbs bund Benolfen ju verhinbern.

Intrag bes Inwalts betrefiend Cmpfeblung eines ड̇demas bei bet Bllanzaufitellang fir Baugenollenldaften. . . . . .

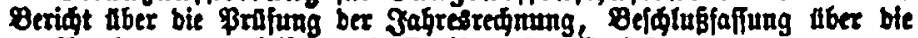
Inerienumang berfelben unb cteilung ber Entfaftung...... 29t

Beridt aber bie Einnabmen unb Elregaben far bas Jabr 1907. : 293

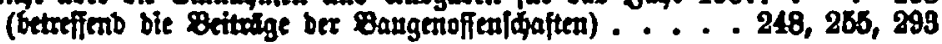


Intrag Insoulte:

Den Benofienfihaften wirb empfoblen, bie Inwendung ber

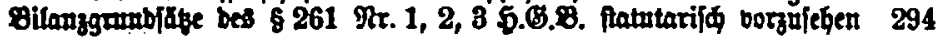

Yutrag bes Befamtauphuffes betreffenb bie Durdfahrung ber "Ber. baubsrevifion" ................. 299

III. Bufammenftellang bet gefaften Bejdiclife ufto. . . . . . . . 333

IV. Beriat aber bie Berbaublangen ber Berfanbsrebiforen . . . . . . 342

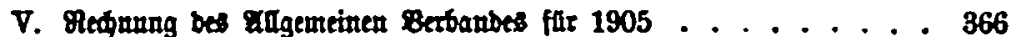

Borminilage fitr 1906 upb $1907 . . . . . . . . . . .378$

VI. \&eridt aber Ditglieberbeftanb unb Mitglieberbewegung in salgemeinen

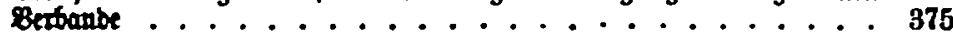

VII. Ripe ber Benofienidaften bes 9ugemeinen Bexbanbes unb Britragstife 378

Anberungen in Beftanbe ber Mitglieber bes Angemeinen Berbanbes 439

Brfammenfellung der unterwetbănbe. . . . . . . . . . . 442

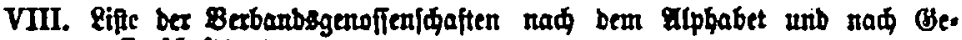
nofeujdaftegattungen ..............443

\section{Beridtignngen.}

Fuf Seite 173 if bei פntrag IV berfebentlid fortgeblicben: „fintrag bes Fabaltg".

Fuf Seite 291 muß es bor bem Beridterfatter heißen: „XI. Berift üher

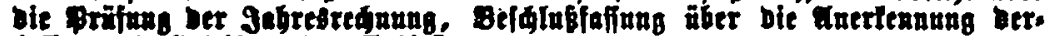
fellen wal Crtelima ber Eatlafung".

Fuf Seite 311, Beile 27 von unten mus es fatt 25000 beisen: „... Gaben wir 21000 in Berbänben ..." 